\title{
Collaboration in multi-tier supply chains for reducing empty running: A case study in the UK retail sector
}

\author{
Melissa Venegas Vallejos ${ }^{\mathrm{a}}$, Aristides Matopoulos ${ }^{\mathrm{b}}$, Andrew Greasley ${ }^{\mathrm{a}}$ \\ ${ }^{a}$ Aston Business School, Aston University, Birmingham, United Kingdom \\ ${ }^{\mathrm{b}}$ Aston Logistics \& Systems Institute, Aston University, Birmingham, United Kingdom
}

\begin{abstract}
This research aims to explore ways to improve transport efficiency in retail multi-tier supply chains by integrating raw material sourcing of suppliers into the transport network. The performance of the proposed scenario is assessed using a discrete-event simulation (DES) model that includes the additional pick-up and drop-off points of an extended transport network. The results suggest an improvement in the transport network efficiency, evidenced in the reduction of empty running levels and costs. This study supports the idea that the integration of raw material sourcing of suppliers into a retailer's transport network can bring significant benefits.
\end{abstract}

\section{Keywords}

Collaboration; Multi-tier supply chains; Transport efficiency; Retail sector; Empty running; Discreteevent simulation

\section{Introduction}

With the rise of domestic freight transport activity and shortage of drivers in Europe, and in the UK, there is a growing interest in improving transport efficiency. The underutilisation of road freight vehicles cost the UK road freight industry more than $£ 160$ million annually and generates 426,000 tonnes of greenhouse gases (GHG) emissions, having a significant impact upon the environment (Department for Transport, 2017). Industries highly dependent on transport such as the automotive industry are facing major empty running problems with $40 \%$ to $50 \%$ of unloaded trips. However, they have recently developed strategies to reduce empty running, such as the use of convertible trailers that can carry both cars and containers. Further policies include combining the inbound flow of car parts and outbound flow of vehicles and making use of big data analysis to find the best routes (Vossebeld, 2017).

The retail industry is an industry that depends heavily on transport, and even though retailers have been helping to reduce empty running levels, there are still opportunities to reduce these levels even further. Retailers have evolved from being passive recipients of goods from manufacturers and suppliers to lead and manage their supply chains from production to consumption (Fernie and Sparks, 2014). After focusing on the efficiency and effectiveness of their operations, retailers have started to adopt more collaborative practices to get even greater benefits (Sparks, 2010; Panahifar et al., 2018). This trend has also been reflected in the literature, with prior research looking at the benefits of supply chain collaboration. Some of these authors have highlighted, in particular, that there are still opportunities to improve supply chain performance by focusing on collaborative transport practices (Chan and Zhang, 2011; Wang and Kopfer, 2014). Many leading retailers have adopted these practices successfully, increasing the annual volume of goods transported by lorry, reducing the kilometres travelled per vehicle and as a consequence cutting down fuel transportation costs (Hingley et al., 2011; Fernie and Sparks, 2014).

Previous research (e.g. Potter, Mason and Lalwani, 2007; Hingley et al., 2011; Accorsi et al., 2018) on collaboration promotes integration across the whole supply chain as a means to improve transport efficiency, but the focus has been primarily between pairs of manufacturers and retailers ignoring other supply chain members. In this research, the focus of analysis is expanded to include lower-tier 
suppliers. This is important since the transport inefficiencies in one link of the supply chain can have a cascading effect on the entire supply chain by transferring the additional cost to the other supply chain members. This research focuses on the food category of a retailer and explores collaboration opportunities with its Tier 2 suppliers (i.e. the raw material suppliers of retailer's direct) and Tier 1 suppliers. The raw material suppliers of this study are commonly small companies that make small deliveries and manage them independently at their own cost. As Pal and Kant (2017) suggest, using private networks or trucks for deliveries without coordination may generate inefficiencies. Therefore, the question guiding this research is: Can the integration of raw material sourcing to suppliers in the existing distribution network of Retailer Alpha increase the transport efficiency of the distribution network?

This research provides several distinct contributions to the supply chain literature. First, it investigates the opportunity to improve transport efficiency through transport collaboration among Tier 2 suppliers, Tier 1 suppliers and retailers, which is an area that requires further development. This research is also expanding supply chain literature by providing new empirical insights through a case study that demonstrate the operational benefits that may be achieved by collaboration with lowertier suppliers. Finally, this research proposes a mixed-method approach and a discrete-event simulation tool that may be used by practitioners to assess the transport efficiency impact of the integration of raw material sourcing to suppliers in an existing retailer distribution network.

This paper is organised as follows. In the next section, the literature will be reviewed to gain knowledge about the topic under investigation, identify the research gaps, and posteriorly state the research question. Then, the research methodology is explained and justified. Afterwards, the case study is conducted, and the simulation methodology is explained in detail. In the next section, the findings are discussed. Finally, the conclusions, research implications, limitations and future research suggestions are presented.

\section{Literature Review}

\subsection{Transport efficiency in road freight}

With domestic freight transport activity increasing globally, and in the UK, in terms of both the amount of goods lifted (i.e. the weight of goods carried, measured in tonnes) and goods moved (i.e. the weight of goods carried, multiplied by the distance hauled, measured in tonne-kilometres) (Department for Transport, 2019; OECD, 2020) there is a growing interest on minimising the economic impact and environmental effect of road freight transport on improving transport efficiency (Arvidsson, Woxenius and Lammga, 2013; Moen, 2016; Fu, 2017; Santén, 2017). Moreover, as the International Road Transport Union (2019) suggests, Europe is facing a shortage of drivers that may affect the road freight transport industry. Therefore, there is a need to explore ways to improve road freight transport efficiency. Aronsson and Huge Brodin (2006) define transport efficiency as providing a transport service with less resource consumption without affecting the logistic performance in terms of cost and service level.

Transport efficiency is dependent on the degree to which the vehicle's capacity can be maximised and used in both directions (Mason and Lalwani, 2006; McKinnon and Ge, 2006). For this reason, one of the most common indicators of vehicle underutilisation is empty running (McKinnon and Ge, 2006). According to Fernie, Sparks and McKinnon (2010) the level of empty running is commonly represented as the proportion of truck-km that run empty ( $\mathrm{km}$ travelled empty/ total $\mathrm{km}$ travelled). For instance, according to a report presented by the European Commission DG for Mobility and Transport (2017), around $26 \%$ of the national road freight journeys in the EU were empty runs. In the UK in particular, $29 \%$ of the domestic road freight vehicles kilometres were run empty (Department for Transport, 2019). Furthermore, in the case of the UK food chain, the percentage was even higher, with a $48 \%$ empty running (Department for Transport, 2019). According to the Department of transport (2017), 
empty running cost the freight industry $£ 160$ million only in fuel a year and generates 426,000 tonnes of GHG emissions. Some authors such as Davies, Mason and Lalwani (2007) have estimated the cost of the UK fleet empty running using not only the UK Road Haulage Association's cost tables for average fuel costs but also the average annual mileage. Even though empty running has been reduced during the last decades (Mason and Lalwani, 2006), there is still scope for further improvement. However, eliminating empty running and thus increasing load factors to approaching $100 \%$ might not be a realistic target for several reasons including the complexity of the variety of operation conditions, geographical differences and scheduling constraints.

\subsection{Collaborative practices to improve transport efficiency in the retail industry}

One of the industries in the UK that has put forward initiatives to improve transport efficiency is the retail industry. Central to the success of these initiatives has been the collaboration between businesses. Collaborative relationships go beyond the regular commercial relationship (Matopoulos et al., 2007) and deliver more powerful advantages than the ones that could be achieved when companies work individually (Panahifar et al., 2018). Prior research has shown that even though individual companies can become more efficient by focusing on the reduction of distance travelled and fuel consumption, better results may be achieved when supply chain members decide to apply collaborative transport practices (Fernie, Sparks and McKinnon, 2010). As a result, many retail companies have been adopting vertical and horizontal collaboration practices to maximise the transport efficiency (Mason and Lalwani, 2006; Hingley et al., 2011; Fernie and Sparks, 2014; Potter, Lalwani and Disney, 2016).

\subsubsection{Vertical collaboration}

Some of the vertical collaboration practices that have been widely used in the retail industry are supplier collection, onward delivery and Factory Gate Pricing (FGP). In the case of supplier collection practice, the shop delivery vehicles instead of returning to a Distribution Centre (DC) empty, can be routed to the suppliers' sites to collect orders and deliver them to the retailer's DC (Mason and Lalwani, 2006; Fernie and Sparks, 2014). Whereas, in an onward delivery practice, the supplier's vehicle offload products at the retailer's distribution centre and backload with goods to the retailer's shops (Fernie and Sparks, 2014). Commonly the suppliers deliver the goods to shop premises that are on the way back to the factory to minimise the time and kilometre deviation (Waters and Rinsler, 2014).

Another strategy applied in retail distribution is FGP. Under FGP, the retailer separates the transport costs that the suppliers impose on the products, assume the cost of the inbound transport and take over control of the transport organisation (McKinnon and Ge, 2006). However, in the logistics sector, the term has a broader meaning and does not just refer to the actual product pricing. As Potter, Lalwani and Disney (2016) suggest, FGP generates not only price transparency, but also better use of vehicle capacity, as well as economic and environmental benefits. As many authors suggest the replication of FGP practices have improved the backhauling and provided retailers with significant control of the inbound distribution (Potter, Mason and Lalwani, 2007; Potter, Lalwani and Disney, 2016),. Many British leading retailers such as Tesco, Asda, Sainsbury have adopted this practice successfully during the last years (Potter, Lalwani and Disney, 2016).

Many authors have given particular attention to FGP research. For instance, Potter, Mason and Lalwani (2007) studied the implementation and impact of FGP in a grocery retailer but from a different perspective. Through a single case study, this paper aimed to identify the main characteristics of an effective FGP implementation and also the benefits and concerns of the adoption at a strategic, tactical and operational level. According to the research findings, the introduction of FGP contributes to the reduction of transport and inventory costs and at the same time increases the service levels. Potter, Lalwani and Disney (2016) studied the impact of FGP on transport and logistics using a modelling approach with the results indicating that a reduction of more than $20 \%$ of the vehicle miles required to get products from suppliers to distribution centres (Potter, Lalwani and Disney, 2016). 


\subsubsection{Horizontal collaboration}

Unlike vertical collaboration, the use of horizontal collaborative practices is limited in retail distribution. Hingley et al. (2011) study the opportunities and limitations of using fourth-party logistics (4PL) management to enhance horizontal collaborations in the retail grocery sector. Using qualitative data collected through interviews with suppliers, Logistic Service Providers (LSPs) and a grocery retailer results showed that despite all the gained and potential benefits of horizontal collaboration in the grocery retail industry only suppliers and LPS are willing to participate in 4PL innovations. In contrast, retailers were less interested in participating due to the fear of losing power and control over suppliers. Moreover, retailers pay more attention to service levels and protection of sales data that could be leaked in case of close collaboration (Hingley et al., 2011). Accorsi et al. (2018) suggested a different approach to the study of horizontal collaboration in retail food supply chains and proposed horizontal communication among vendors to optimise the daily deliveries of goods and reduce transport costs. Their results confirmed significant reductions in delivery transport costs and increased service levels.

\subsection{Simulation applications}

According to the literature, the use of simulation as a decision support system in retail distribution is receiving significant attention (Thron, Nagy and Wassan, 2007; Lim and Shiode, 2011; Greasley and Assi, 2012; Buijs, Danhof and Wortmann, 2016). As Thierry et al. suggest (2008), mathematical models are sometimes impractical to reflect realistic cases, and experimentations may have technical or cost limitations. In contrast, simulation systems can be easily used to represent the model of a more realistic operation system and evaluate what-if scenarios. Discrete-event simulation (DES), in particular, is used to model systems that have individual entities whose behaviour can be represented by a series of events that may change the state of the system (Greasley, 2019). Jahangirian et al. (2010) suggest that DES is arguably the most popular Operational Research technique.

Many authors have demonstrated the usefulness of DES in the retail distribution context. For instance, Buijs, Danhof and Wortmann (2016) developed a discrete-event simulation model to represent and evaluate two holistic cross-docking management solutions that involve an adaptation in the design and control of the retailer's distribution network. The suggested model simulates the initial and proposed cross-docking activities that take place inside the distribution centres as well as the inbound and outbound operations using real company data as input. Greasley and Assi (2012) similarly, built up a discrete-event simulation model to test some delivery policy changes in a hub and spoke freight distribution system. The model was used to assess the performance of the first delivery policy for retail and non-retail customers in comparison to a new policy that separates deliveries for each type of customer (retail and non-retail). Thron, Nagy and Wassan (2007) also used a DES model to assess a set of changes in the distribution of food manufacturers to retailers' DC. The changes that the authors proposed to improve the delivery framework were related in particular to demand and sales transparency achieved through information collaboration between manufacturer and retailers.

From the review of the literature, it is evident that there is a need to improve the efficiency of road freight transport due to the high levels of underutilisation (Department for Transport, 2017) and shortage of drivers (International Road Transport Union, 2019). Even though retailers have made an essential contribution to reducing these levels, there are still opportunities for further reductions. Previous research typically focused on integration along the chain between pairs of manufacturers and retailers ignoring other supply chain members as it was confirmed in the literature review (Potter, Mason and Lalwani, 2007; Hingley et al., 2011; Potter, Lalwani and Disney, 2016; Accorsi et al., 2018). Therefore, this research aims at bridging this gap by expanding the focus of analysis to include lowertier suppliers to improve transport efficiency through a different collaborative strategy. The question guiding this research is: Can the integration of raw material sourcing to suppliers in the existing distribution network of Retailer Alpha increase the transport efficiency of the distribution network? 
Hence, this research contributes to the literature by exploring the potential for transport collaboration among Tier 2 suppliers, Tier 1 suppliers and retailers to achieve greater transport efficiency in the retail supply chain.

\section{Research methodology}

\subsection{Research context and approach}

Due to the exploratory nature of this research, a case study approach was selected, since it provides an exemplar practice of a real-life situation in-depth and within in its original context to get more precious insights (Yin, 2009; Denzin and Lincoln, 2011). Besides, case studies may benefit from having access to multiple sources of evidence to conduct research (Scholz and Tietje, 2002). Single case studies have also been widely used in the past to study transport efficiency in the retail industry because of their greater applicability in comparison to other traditional methods (Potter, Mason and Lalwani, 2007; Hingley et al., 2011; Potter, Lalwani and Disney, 2016; Accorsi et al., 2018). This paper presents a case study of an international multi-channel retailer that sells branded food, clothing and home products in its stores and online. This research was decided to focus on the distribution of food products since it is one of the most common commodities transported by UK HGVs with 282 million tons lifted in 2018 which represent 20\% of the total transported (Department for Transport, 2019). In this case study, one of the several Regional Distribution Centres (RDC), RDC X, was chosen to be analysed and in particular, the category of fresh goods and processed food transport which currently has the highest levels of empty running and underutilisation of lorries. Regarding the data collection methods, a mixed-method approach was chosen to be followed using qualitative and quantitative methods. For this research, primary data was collected through interviews and questionnaires, and secondary data was collected from company records. For this study, all the numerical information presented about the analysis of the company records and questionnaires was multiplied by a factor. The use of this factor allows the researcher to avoid the use of the company's real data but still gives an approximation of a real industry case study. For this research, the simulation study methodology proposed in Greasley (2004) that includes the following steps was chosen: Study objectives, Data collection and process mapping, Modelling input data, building the model, verification and validation, experimentation, results.

\subsection{Data collection}

Firstly, primary data was collected through interviews with the Food Supply Chain Manager of Retailer Alpha, who is responsible for the primary distribution, secondary distribution and E-commerce of chilled and frozen food. The first part of the questionnaire contains questions about the general configuration of the distribution network and its participants. The second part deals specifically with the distribution of short life, chilled and ambient food, in order to identify the problem areas. For the next stage, secondary data from company records were collected. This data corresponded to 176 journeys of 78 lorries from RDC $X$ to the different 66 Retailer Alpha stores that are located in the surrounding areas to RDC X. The historical records requested to the company were the journey summary reports that include vehicles routes, arrival/departure time and distance from/to RDC X and stores, time, type of journey, loading information. Such records were used to analyse the current situation of the retailer's distribution network in terms of performance and efficiency levels. After that, primary data was collected through online questionnaires to identify the potential suppliers of raw material deliveries that may be added to the retailer's distribution network. From the 24 suppliers of short life, chilled and ambient food that supply food to RDC X, it was identified that some of them had their own suppliers in the areas covered by the store delivery trucks that depart and return to RDC X. Therefore, twelve questionnaires were sent through email to these retailer's suppliers to conduct this research. These questionnaires included both multiple-choice and close questions mainly related to potential suppliers and the correspondent geographical locations of the potential new pick-up and 
drop-off points, weekly volumes, deliveries frequency. This latter information was used as input for the potential improved simulation model that includes the new deliveries between Tier 2 suppliers and Tier 1 suppliers to assess its correspondent efficiency improvements.

\section{Case study}

\subsection{Retailer Alpha Distribution network}

In the first part, the qualitative data collected through the interviews with the supply chain manager was analysed to understand the research context and how the overall food supply chain network works. Both primary and secondary distribution processes are illustrated in Figure 1. In the case of primary distribution, the chilled, short life and frozen food are collected from more than 100 suppliers' sites, sent to a consolidation centre and posteriorly delivered to the RDCs. The second part of the Food supply chain network involves the secondary distribution network (See Figure 1). The products stored in the RDCs are delivered to nearly 1000 Retailer Alpha stores seven days a week.

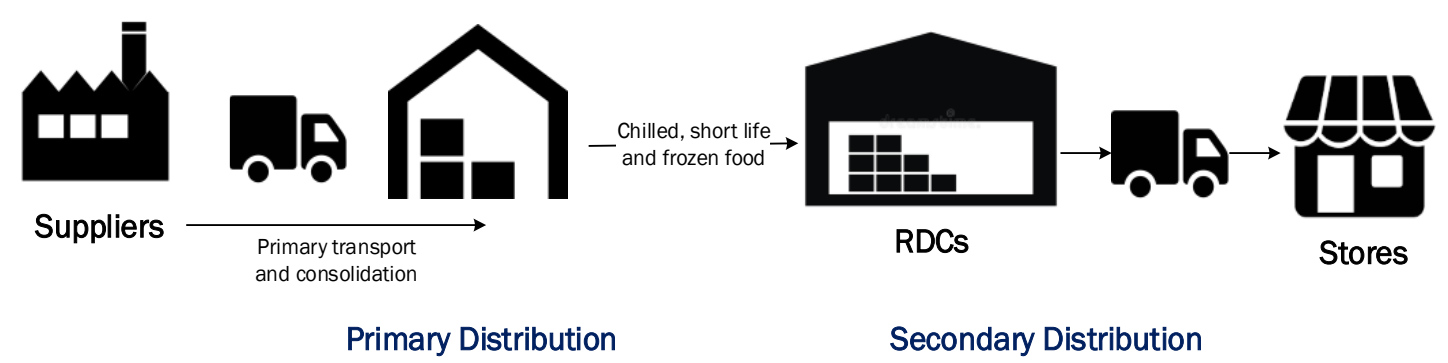

Figure 1. A schematic overview of the Food Supply Chain

During the call meetings, the Food Supply Chain manager stated that their main concern was the high empty running levels of the store delivery trucks. According to the Food Supply Chain team, in order to manage the distribution, Retailer Alpha has contracts with different hauliers that operate independently. Supply costs are agreed directly with and paid to Retailer Alpha. It was found that a significant number of Retailer Alpha suppliers of primary product such as meat, fish, poultry, bread etc. also supply raw materials to other Retailer Alpha Tier 1 suppliers for use in processed chilled foods. However, Retailer Alpha Tier 1 suppliers of processes food manage their supply independently with suppliers' vehicles and/or other haulier companies. Moreover, it was identified that Retailer Alpha's distribution network has hundreds of vehicles already moving in proximity to the Tier 1 and Tier 2 sites. Hence, it was decided to assess the current opportunity to expand the transportation network to integrate raw material sourcing to suppliers.

\subsection{Empty journeys store delivery vehicles}

A detailed analysis of the performance of store delivery trucks was developed to assess the initial performance and compare it with the new proposed scenario. The first indicator chosen to be analysed was the level of empty running since it is the most common and visible indicator of vehicle underutilisation (McKinnon and Ge, 2006). Empty journeys were assessed in terms of distance travelled and man-hour. According to the statistics of journeys in Table 1, 40.5\% of the Km travelled by the store delivery lorries were run empty, while $20 \%$ of the hours were dedicated to empty journeys (Table 1). 
Table 1. Descriptive statistics of journeys per week

\begin{tabular}{|ccccc|}
\hline Type of Journey & Kilometres & Percentage & Man-Hours & Percentage \\
\hline Empty Journeys & 18,526 & $40.5 \%$ & 240 & $20 \%$ \\
\hline Loaded Journeys & 27,217 & $59.5 \%$ & 962 & $80 \%$ \\
\hline Total & $\mathbf{4 5 , 7 4 3}$ & $100 \%$ & $\mathbf{1 , 2 0 2}$ & $100 \%$ \\
\hline
\end{tabular}

An economic analysis was used similar to the one performed by Davies, Mason and Lalwani (2007) that estimated the annual fuel and driver costs associated with the empty running. The cost was estimated based on two components: fuel cost and driver cost. According to the results, the total fuel cost of the empty running of one week of operation is $f 5,858$ (See Table 2). In the case of the driver cost the total drivers' cost of one week of operation was $f 5,711$. Therefore, the total cost of the empty journeys of one week was $£ 11,570$ (Sum of fuel and driver cost) and $£ 601,614$ if calculated annually.

Table 2. Fuel and driver cost

\begin{tabular}{|lc|}
\multicolumn{2}{|c|}{ Fuel cost } \\
\hline Consumption (litres/km) & 0.326 \\
\hline Fuel price (f/litre) & 0.97 \\
\hline Empty journeys (Km/week) & 18,526 \\
\hline Total Fuel cost (Weekly) & $\mathbf{£ ~ 5 , 8 5 8}$ \\
\hline
\end{tabular}

\begin{tabular}{|lc|}
\hline \multicolumn{2}{|c|}{ Driver cost } \\
\hline Average driver cost (£/hour) & 23.75 \\
\hline Empty journeys (Hour/week) & 240 \\
\hline & \\
\hline Total Driver cost (Weekly) & $\mathbf{5 5 , 7 1 1}$ \\
\hline
\end{tabular}

\subsection{Simulation Study of the current situation}

For this research, the simulation study methodology proposed in Greasley (2004) was employed.

\subsubsection{Study Objectives}

- Model the secondary distribution network of Retailer Alpha by focusing on the routes followed by the store delivery lorries from the RDC to the correspondent stores and their return to the RDC.

- Propose a new scenario and simulate it to evaluate the best way to reduce the empty running levels and costs of the expanded distribution network.

\subsubsection{Data Collection and process mapping}

As it was stated previously, the data for this study was collected through interviews, company records and questionnaires to suppliers. The interviews with the Food Supply Chain Manager of Retailer Alpha provided useful insights about main distribution processes to be studied. The data from the company records was processed and the relevant information used for model input data. The data collected through the questionnaires to suppliers was used to define procedures for the simulation model that include the new deliveries between Tier 2 and Tier 1 suppliers.

Before building up the model of the current secondary distribution network, it is essential to create a process map that represents the sequence of steps in the process to be analysed. Figure 2 , shows the main activities and steps that take place along a less-than-truckload (LTL) route including the departure from the depot, deliveries to a minimum of two stores and the way back to the initial depot. It is essential to mention that the process map shown in Figure 2 shows a simplified map that does not include any disruption in the trip such as breaks or any other occasional stops that are not part of the main process to be analysed. 


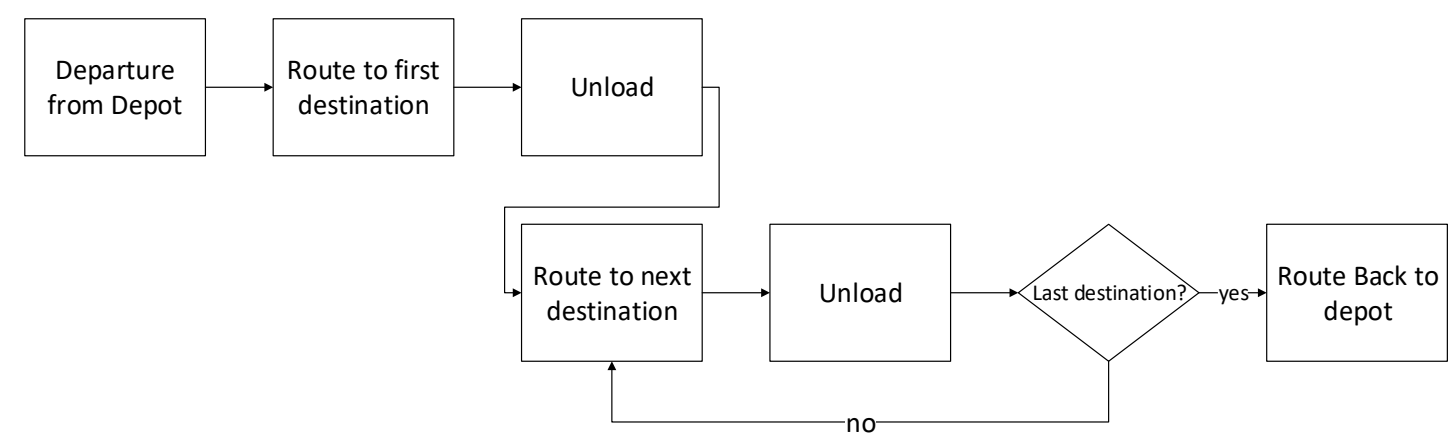

Figure 2. Less-than-truckload (LTL) route model

\subsubsection{Modelling Input Data}

For the simulation analysis Arena Software 15.1. was used. The Input Analyser tool of the software was used to analyse a sample of the data collected, fit it to the most suitable distribution and add variability to the simulation model. The distribution that needed to be determined was the unloading time.

\subsubsection{Building the Model}

The current situation of the secondary distribution network was built using the ARENA discrete-event simulation software following the process map of lorries journeys in Figure 2. The software allowed the building up of a complex transportation network and the use of Microsoft Excel spreadsheets to hold input data. The entities of the model are the lorries and to represent the stores and sequences the modules STATION and ROUTE were used. The schedule information, including routing sequences and timings, were uploaded to the simulation model as Attributes and Array Variables.

\subsubsection{Verification and Validation}

Before analysing the results of the simulation model, it is necessary to ensure that the model built provides a valid representation of the system under study. In order to do so, the verification and validation processes were performed. The verification process aims to ensure that the model build using the software is a correct representation of the process map of the system (Greasley, 2004). While the validation process is used to assure that the model behaves close enough to the real system under examination (Greasley, 2004).

In order to perform the verification of the model, the animation inspection was selected. The animation inspection was conducted by reducing the speed of the simulation to verify that the entities were moving following the correct sequences. The outcome of the verification was that the entities in the model were following the route sequences correctly. A validation process was also performed to check the precision of the model by comparing it with the real system. Four indicators (see Table 3) were chosen to validate if the model results were similar to the ones in the real system. After comparing the results, it is possible to affirm that the deviation is low and the results are quite close with a maximum of $5 \%$ deviation and a minimum of approximately $0.5 \%$.

Table 3. Comparison between Real System and Simulation results for validation

\begin{tabular}{|lc|c|c|}
\hline & Real data results & Current model results & Deviation \\
\hline Average journey (min) & 484 & 508 & $5 \%$ \\
\hline Unloading time (min) & 173 & 178 & $3 \%$ \\
\hline Empty running (\% km) & $40.5 \%$ & $40.0 \%$ & $0.5 \mathrm{pp}$ \\
\hline Empty running (\% man-hour) & $20.0 \%$ & $18.1 \%$ & $1.9 \mathrm{pp}$ \\
\hline
\end{tabular}




\subsubsection{Experimentation}

With the information collected through the online questionnaires and the previous data analysis, the new model for the extended distribution network was built, including the additional steps shown in Figure 3. The new model besides the deliveries from RDC to Retailer Alpha stores, includes the deliveries from Tier 2 suppliers to Tier 1 suppliers and the new steps along with a new decision point. The new decision point decides if the lorry should go straight back to the depot or to a new station to pick-up goods from a Tier 2 supplier, then to drop them off in a Tier 1 supplier premise and finally go back to the depot.

To decide which lorries should do the additional pick-ups and drop-offs an Array variable was created in the Arena model. This model includes the number of the route, the time to route from the last location to pick-up point, the time from pick-up to drop-off, the time from drop-off to base, pick-up load time and drop-off unload time. The information used to build the array variable was obtained through the questionnaires sent to suppliers and complemented with a location mapping. The mapping analysis was crucial to identify the locations of Retailer alpha Tier 1 and Tier 2 suppliers. It also was used to verify if their locations were close to the way back to the RDC X. Google Maps tools were also used to measure the distance between pick-up and drop-off points and their correspondent trip durations. The pick-up and drop-off points that did not demand a significant deviation were added to the simulation model as part of the lorries' journeys.

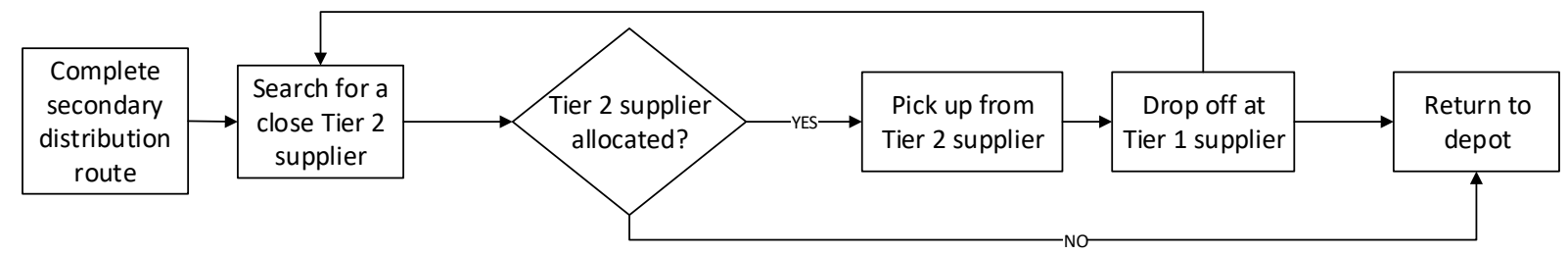

Figure 3. Process map of the extended model

\subsubsection{Results}

The results of the simulation analysis of the current secondary distribution network and its potential expansion that includes the sourcing from Retailer Alpha Tier 2 to Tier 1 suppliers are summarised in Table 4. This table compares the Real data results and the potential improved scenario of one week of operations in RDC X. The results suggest that the new scenario provides significant improvements. Firstly, the empty running expressed measured as a percentage of kilometres reduces by $14 \%$. Secondly, the empty journeys measured as a proportion of the man-hour reduces by 3 percentage point. Finally, the cost of the weekly empty running (Fuel cost + Driver cost) reduces by $f 1,432$, which represents a reduction of $12 \%$.

Table 4. Results from the overall analysis per week

\begin{tabular}{|c|c|c|}
\hline & $\begin{array}{l}\text { Current situation } \\
\text { before expansion }\end{array}$ & $\begin{array}{l}\text { Potential scenario } \\
\text { simulation results }\end{array}$ \\
\hline Empty running (\% km) & $40.5 \%$ & $26.1 \%$ \\
\hline Empty running (\% man-hour) & $20.0 \%$ & $17.1 \%$ \\
\hline Empty running Fuel cost & f 5,858 & 4,486 \\
\hline Empty running Driver cost & f 5,711 & 5,652 \\
\hline Empty running Total Cost & f 11,570 & f 10,138 \\
\hline
\end{tabular}

\section{Discussion}

An overall review of the Retailer Alpha distribution network operations was performed to identify the main improvement opportunities. It was identified that the secondary distribution network had high empty running levels; therefore, there was an opportunity to use the existing spare capacity. In this 
particular case, transport collaboration between Tier 2 supplier, Tier 1 suppliers and retailer was proposed to increase the distribution network efficiency and reduce the associated costs. This decision was made in consonance with the literature findings that suggested that there were still opportunities to improve supply chain performance by focusing on collaborative transport practices (Chan and Zhang, 2011; Wang and Kopfer, 2014).

The secondary distribution network of Retailer Alpha was investigated by analysing company records in the form of journey summary reports. The first indicator chosen to be analysed was the empty running since, as McKinnon and Ge (2006) suggest, is the most common and visible indicator of vehicle underutilisation. The results of the first part of the analysis have shown that the empty running levels of the RDC X reached the $40.5 \%$ which is in line with the UK food chain empty running levels that reached 38\% according to previous research of the Department of Transport (2017). Then, the time consumption of the empty journey was also decided to be measured as a percentage of man-hour, which, according to the analysis, was $20 \%$ for this particular case. Moreover, to do an economic analysis similar to the one performed by Davies, Mason and Lalwani (2007) the empty journey features were used to estimate the annual fuel and driver costs associated with empty running.

To expand the current research on supply chain collaboration that has primarily studied the collaboration along the chain between pairs of manufacturers and retailers ignoring other supply chain members (Potter, Mason and Lalwani, 2007; Hingley et al., 2011; Potter, Lalwani and Disney, 2016; Accorsi et al., 2018) the sourcing between Retailer Alpha Tier 2 and Tier 1 suppliers was investigated. Questionnaires were used to identify the expansion opportunity in terms of the general characteristics of the new deliveries, the location of the new pick-up and drop-off points to measure the integration effect.

In line with the findings from the literature (Thron, Nagy and Wassan, 2007; Lim and Shiode, 2011; Greasley and Assi, 2012; Buijs, Danhof and Wortmann, 2016) that highlighted the benefits of simulation as a decision support system in the retail distribution context, a simulation model was employed. This simulation model was used to represent the current secondary distribution network operations and assess the efficiency impact of the network's expansion (including the sourcing between Retailer Alpha Tier 2 and Tier 1 suppliers) having the following results:

- Empty running measured as a percentage of kilometres travelled reduced from $40.5 \%$ to $26.1 \%$.

- Empty journeys measured as a proportion of the man-hour reduced by 3 percentage point.

- The cost of the empty running (Fuel cost + Driver cost) in RDC X reduced by $12 \%$, which represents f74,464 savings per year.

The results suggest that the integration of the raw material sourcing to suppliers into the secondary distribution network of Retailer Alpha decreases the empty running levels and costs significantly. As a consequence, the proposed scenario increases the efficiency of the distribution network. This is in line with what Chan and Zhang (2011) and Wang and Kopfer (2014) claimed that there were still more opportunities to improve the supply chain performance through transport collaboration.

\section{Conclusions}

The present paper set out to answer the following research question: Can the integration of raw material sourcing to suppliers in the existing distribution network of Retailer Alpha increase the transport efficiency of the distribution network?. This research investigates the integration of the secondary distribution network of a retailer and the retailer's suppliers sourcing. By doing predictive analysis and building a simulation model to compare the current situation and proposed scenario of the distribution network, the case study was analysed. Regarding the research question, the study confirmed that the proposed distribution integration increases the transport efficiency of the network by reducing its empty running levels and costs. Moreover, the proposed methodology that includes a 
discrete-event simulation has proved to be a useful tool to make this evaluation due to its usefulness to represent a realistic distribution network and versatility to assess changes in the original configuration before a real implementation.

\subsection{Research and practical implications}

This study contributes to the knowledge by complementing the supply chain collaboration research that mainly focuses on the collaboration between Tier 1 suppliers and retailers. Hence, this research explores opportunities to improve transport efficiency through the collaboration among Tier 1 suppliers, Tier 2 supplier and retailers. This case study shows that collaboration with lower-tier suppliers in the retail supply chain can increase transport efficiency. This paper proposes a mixedmethod approach and a discrete-event simulation tool that may be used by practitioners to assess the transport efficiency impact of the integration of raw material sourcing to suppliers in an existing retailer distribution network. Moreover, this research uses a simulation model that can be easily adapted in terms of routes, stations (e.g. stores, supplier sites), entities (e.g. lorries) to represent a real retailer's distribution network. The initial model can be posteriorly adapted to represent a new improved scenario that besides the store deliveries includes the deliveries from Tier 2 suppliers to Tier 1 suppliers to compare the results that can be achieved through a collaborative strategy.

\subsection{Limitations and future research}

This research contributes to the supply chain collaboration literature, but it is not without limitations. First, the use of a single case study and the focus on food products may be considered as a limitation since other types of retailers' distribution network and suppliers can operate under different conditions and can have different network configurations. Another limitation is related to the lorry journey data used as input for the simulation model. More specifically, the data used as input corresponding to one week of operations which does not allow to represent a weekly or monthly pattern which may be necessary for a development phase. Additionally, the human factor that affects journeys length and transport efficiency has not been explored in the present research. Another limitation of this study is that it does not include the indirect costs of management and planning associated with the new collaboration system, which can affect the savings estimations.

For future research, the human factor effect in transport efficiency could be explored. The driving habits of lorry drivers could be widely explored to identify how the driving style, including excessive speed and harsh braking, affect fuel efficiency. Future work should also include the evaluation of indirect costs and other transport efficiency indicators such as vehicle load factor and space utilisation to complement the efficiency analysis. By using other indicators, it would be possible to have a more accurate estimation of the variation of the efficiency levels and savings achieved through a distribution network expansion. For future research, it could be possible to include non-food items in the analysis to identify further saving opportunities. Finally, further research is recommended to explore not only the integration of suppliers' sourcing to the secondary distribution network but also include the primary distribution network to such integration since it may be argued that there are still missed efficiency opportunities that can be achieved by using the spare capacity of the primary distribution network. 


\section{References}

Accorsi, R. et al. (2018) 'On the design of cooperative vendors' networks in retail food supply chains: a logistics-driven approach', International Journal of Logistics Research and Applications. Taylor \& Francis, 21(1), pp. 35-52.

Aronsson, H. and Huge-Brodin, M. (2006) 'Environmental impact of changing logistics structures', The International Journal of Logistics Management, 17(3), pp. 394-415.

Arvidsson, N., Woxenius, J. and Lammga, C. (2013)' Review of Road Hauliers' Measures for Increasing Transport Efficiency and Sustainability in Urban Freight Distribution', Transport Reviews, 33(1), pp. 107-127.

Banks, J. et al. (2010) Discrete-Event System Simulation. 5th edn. Upper Saddle River, NJ: Prentice Hall.

Buijs, P., Danhof, H. W. and Wortmann, J. H. C. (2016) 'Just-in-Time Retail Distribution: A Systems Perspective on Cross-Docking', Journal of Business Logistics, 37(3), pp. 213-230.

Chan, F. T. S. and Zhang, T. (2011) 'The impact of Collaborative Transportation Management on supply chain performance: A simulation approach', Expert Systems With Applications. Elsevier Ltd, 38, pp. 2319-2329.

Davies, I., Mason, R. and Lalwani, C. (2007) 'Assessing the impact of ICT on UK general haulage companies', in International Journal of Production Economics. Elsevier, pp. 12-27.

Denzin, N. K. and Lincoln, Y. S. (2011) The SAGE handbook of qualitative research. Thousand Oaks, CA ; London : SAGE, C2011.

Department for transport (2017) Transport Statistics Great Britain 2017. Available at: https://www.gov.uk/government/uploads/system/uploads/attachment_data/file/664323/tsgb2017-print-ready-version.pdf.

Department for Transport (2017) Freight Carbon Review. London. Available at: https://assets.publishing.service.gov.uk/government/uploads/system/uploads/attachment_data/file /590922/freight-carbon-review-2017.pdf.

Department for Transport (2019) Domestic Road Freight Statistics, United Kingdom 2018. London. Available at:

https://assets.publishing.service.gov.uk/government/uploads/system/uploads/attachment_data/file /815839/domestic-road-freight-statistics-2018.pdf.

European Commission DG for Mobility and Transport (2017) An Overview of the EU Road Transport Market in 2015, European Commission. Available at:

https://ec.europa.eu/transport/sites/transport/files/mobility-package-overview-of-the-eu-roadtransport-market-in-2015.pdf.

Fernie, J. and Sparks, L. (2014) Logistics and retail management : emerging issues and new challenges in the retail supply chain. London : Kogan Page, 2014.

Fernie, J., Sparks, L. and McKinnon, A. C. (2010) 'Retail logistics in the UK: past, present and future'.

Fu, J. (2017) Evaluating and Improving the Transport Efficiency of Logistics Operations. KTH Royal Institute of Technology.

Greasley, A. (2004) Simulation modelling for business. Aldershot: Ashgate, 2004. (Innovative business textbooks). 
Greasley, A. (2019) Simulating Business Processes for Descriptive, Predictive, and Prescriptive Analytics. De Gruyter.

Greasley, A. and Assi, A. (2012) 'Improving "last mile" delivery performance to retailers in hub and spoke distribution systems', Journal of Manufacturing Technology Management, 23(6), pp. 794-805. doi: 10.1108/02656710210415703.

Hingley, M. et al. (2011) 'Using fourth-party logistics management to improve horizontal collaboration among grocery retailers', Supply Chain Management: An International Journal VO - 16. Emerald Group Publishing Limited.

International Road Transport Union (2019) Tackling driver shortage in Europe. Available at: https://www.ecta.com/resources/Documents/Other publications/Tackling the European Driver Shortage - IRU report.pdf.

Jahangirian, M. et al. (2010) 'Simulation in manufacturing and business : A review', European Journal of Operational Research. Elsevier BV, 203(1), pp. 1-13.

Lim, H. and Shiode, N. (2011) 'The impact of online shopping demand on physical distribution networks: a simulation approach', International Journal of Physical Distribution \& Logistics Management, 41(8), pp. 732-749.

Mason, R. and Lalwani, C. (2006) 'Transport integration tools for supply chain management', International Journal of Logistics, 9(1), pp. 57-74.

Matopoulos, A. et al. (2007) 'A conceptual framework for supply chain collaboration: Empirical evidence from the agri-food industry', Supply Chain Management: An International Journal, 12(3), pp. 177-186.

McKinnon, A. C. and Ge, Y. (2006) 'The potential for reducing empty running by trucks: a retrospective analysis', International Journal of Physical Distribution \& Logistics Management, 36(5), pp. 391-410.

Moen, O. (2016) 'The Five-step Model - Procurement to Increase Transport Efficiency for an Urban Distribution of Goods', Transportation Research Procedia. Elsevier BV, 12(June 2015), pp. 861-873.

OECD (2020) Freight transport (indicator). Available at: https://data.oecd.org/transport/freighttransport.htm.

Pal, A. and Kant, K. (2017) 'A Food Transportation Framework for an Efficient and Worker-Friendly Fresh Food Physical Internet', Logistics, pp. 1-21.

Panahifar, F. et al. (2018) 'Supply chain collaboration and firm's performance', Journal of Enterprise Information Management, 31(3), pp. p358-379.

Potter, A., Lalwani, C. and Disney, S. M. (2016) 'Modelling the Impact of Factory Gate Pricing on Transport and Logistics', (November 2017).

Potter, A., Mason, R. and Lalwani, C. (2007) 'Analysis of factory gate pricing in the UK grocery supply chain', International Journal of Retail \& Distribution Management, 35(10), pp. 821-834.

Santén, V. (2017) 'Towards more efficient logistics: increasing load factor in a shipper's road transport', The International Journal of Logistics Management, 28(2), pp. 228-250.

Scholz, R. and Tietje, O. (2002) Embedded Case Study Methods. Thousand Oaks, California: SAGE Publications, Inc.

Sparks, L. (2010) 'Supply Chain Management and Retailing', 11, pp. 4-13. 
Thierry, C., Thomas, A. and Bel, G. (2008) Simulation for supply chain management. London : ISTE

Thron, T., Nagy, G. and Wassan, N. (2007) 'Evaluating alternative supply chain structures for perishable products', The International Journal of Logistics Management, 18(3), pp. 364-384.

Vossebeld, R. (2017) How Can We Reduce Empty Runs in Automotive Logistics?, All things Supply Chain. Available at: https://www.allthingssupplychain.com/how-can-we-reduce-empty-runs-inautomotive-logistics/ (Accessed: 1 April 2020).

Wang, X. and Kopfer, H. (2014) 'Collaborative transportation planning of less-than-truckload freight.', OR Spectrum, 36(2), pp. 357-380.

Waters, C. D. J. and Rinsler, S. (2014) Global logistics : new directions in supply chain management. London, United Kingdom ; Philadelphia, PA, USA : Kogan Page

Yin, R. K. (2009) Case study research : design and methods. Los Angeles : Sage Publications, (C2009. (Applied social research methods series: v.5). 